\title{
Sox2 promotes expression of the ST6Gal-I glycosyltransferase in ovarian cancer cells
}

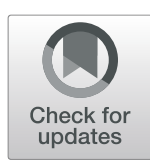

Kaitlyn A. Dorsett, Robert B. Jones, Katherine E. Ankenbauer, Anita B. Hjelmeland and Susan L. Bellis (1)

\begin{abstract}
Background: The ST6Gal-I glycosyltransferase, which adds a2-6-linked sialic acids to N-glycosylated proteins is upregulated in a wide range of malignancies including ovarian cancer. Prior studies have shown that ST6Gal-Imediated sialylation of select surface receptors remodels intracellular signaling to impart cancer stem cell (CSC) characteristics. However, the mechanisms that contribute to ST6Gal-I expression in stem-like cancer cells are poorly understood.

Results: Herein, we identify the master stem cell transcription factor, Sox2, as a novel regulator of ST6Gal-I expression. Interestingly, SOX2 and ST6GAL1 are located within the same tumor-associated amplicon, 3q26, and these two genes exhibit coordinate gains in copy number across multiple cancers including $~ 25 \%$ of ovarian serious adenocarcinomas. In conjunction with genetic co-amplification, our studies suggest that Sox2 directly binds the ST6GAL1 promoter to drive transcription. ST6Gal-I expression is directed by at least four distinct promoters, and we identified the P3 promoter as the predominant promoter utilized by ovarian cancer cells. Chromatin Immunoprecipitation (ChIP) assays revealed that Sox2 binds regions proximal to the P3 promoter. To confirm that Sox2 regulates ST6Gal-1 expression, Sox 2 was either overexpressed or knocked-down in various ovarian cancer cell lines. Sox2 overexpression induced an increase in ST6Gal-I mRNA and protein, as well as surface a2-6 sialylation, whereas Sox2 knock-down suppressed levels of ST6Gal-I mRNA, protein and surface a2-6 sialylation.

Conclusions: These data suggest a process whereby SOX2 and ST6GAL1 are coordinately amplified in cancer cells, with the Sox2 protein then binding the ST6GAL1 promoter to further augment ST6Gal-I expression. Our collective results provide new insight into mechanisms that upregulate ST6Gal-I expression in ovarian cancer cells, and also point to the possibility that some of the CSC characteristics commonly attributed to Sox2 may, in part, be mediated through the sialyltransferase activity of ST6Gal-I.
\end{abstract}

Keywords: Sialic acid, ST6Gal-I, Sox2, 3q26 amplicon, Cancer stem cells, Ovarian cancer

\section{Introduction}

Ovarian cancer is the deadliest gynecological malignancy due primarily to late detection and development of drug resistance $[1,2]$. While most ovarian cancer patients respond initially to treatment, acquired resistance is common, leading to tumor recurrence [2]. Cancer stem cells (CSCs) are thought to be principal drivers of ovarian cancer progression and recurrence due to their high degree of resistance to both chemotherapy and microenvironmental stressors such as hypoxia [3, 4]. Thus, extensive research is focused on the molecular

\footnotetext{
* Correspondence: bellis@uab.edu

Department of Cell, Developmental and Integrative Biology, University of Alabama at Birmingham, MCLM 350, 1918 University Boulevard, Birmingham, AL 35294, USA
}

mechanisms that promote a CSC phenotype. However, the potential role of glycosyltransferases, and their cognate glycan structures, in CSC behavior has received limited attention.

One of the predominant glycosyltransferases upregulated in ovarian and other cancers is ST6Gal-I, a sialyltransferase that adds $\alpha 2-6$-linked sialic acids to $\mathrm{N}$-glycosylated proteins destined for the cell surface or secretion [5-8]. High expression of ST6Gal-I is correlated with decreased overall and progression free survival in patients with high-grade serous ovarian carcinoma $[9,10]$, the most common and aggressive subtype [1]. ST6Gal-I regulates tumor cell phenotype by modulating the sialylation, and therefore function, of key receptors that drive malignant cell behaviors [11-17]. We 
and others have shown that ST6Gal-I activity confers all of the hallmark features of a CSC including increased expression of canonical CSC markers [18], invasive potential $[16,19]$, tumor-initiating potential $[9,20]$, and resistance to hypoxia, chemotherapeutics, and radiation [14, 20-25].

In addition to CSCs, ST6Gal-I expression is enriched in select stem/progenitor niches within normal tissues, such as the basal layer of epidermis and fallopian tube fimbriae $[9,18]$. In contrast, ST6Gal-I expression is negligible in many differentiated cell populations such as ovarian surface epithelium and pancreatic acinar cells [9]. Despite these cell type-specific differences in the levels of ST6Gal-I, there is limited knowledge regarding the mechanisms that regulate ST6Gal-I expression. ST6Gal-I regulation is known to be complex, as there are multiple ST6Gal-I mRNA isoforms [26-29]. These diverse mRNA species are transcribed from at least four promoters: $\mathrm{P} 1$, which is liver selective; $\mathrm{P} 2$, which is utilized exclusively by B cells; P3, a ubiquitously-utilized promoter; and $\mathrm{P} 4$, which is active in the mammary gland during lactation [26-32]. In cancer cells, ST6Gal-I upregulation appears to be directed primarily by the P1 or P3 promoter [30, 33-35].

ST6Gal-I is dramatically upregulated upon transduction of somatic cells with the four Yamanaka factors to generate induced pluripotent stem cells (iPSCs) [18, 36], and knock-down of ST6Gal-I hinders transition to pluripotency [37]. One of the Yamanaka factors is Sox2, suggesting potential regulation of ST6Gal-I by this stem cell-associated transcription factor. Moreover, several studies have reported a strong correlation between the mRNA levels of Sox2 and ST6Gal-I [38-40]. Like ST6Gal-I, Sox2 is upregulated in ovarian cancer [41-43], and its expression is particularly enriched in the CSC population of many different malignancies [44-46]. Both Sox 2 and ST6Gal-I play causal roles in promoting CSC characteristics $[9,25,47]$. Interestingly, the SOX2 and ST6GAL1 genes lie within the same amplicon, referred to as "3q26", which spans from 3q26-3q29 [48-50]. The $3 q 26$ amplicon is one of the most commonly amplified genomic regions across many cancer types, and it functions as a multigenic driver of human cancer [48]. Amplification of the 3q26 region represents an early event in tumorigenesis, and has been associated with enhanced aggressiveness and stem-like properties of epithelial cancers $[48,51]$. While several genes within this amplicon have been implicated in neoplastic transformation, such as SOX2, PI3KCA and ECT2 [48], the potential role of ST6Gal-I in the tumor-promoting activity of the $3 \mathrm{q} 26$ amplicon has gone unnoticed.

In the current study we investigated a novel function for Sox2 in regulating the expression of ST6Gal-I. We first analyzed The Cancer Genome Atlas (TCGA) databases for copy number alterations in SOX2 and
ST6GAL1 and showed that these two genes are coordinately amplified in patient specimens across a wide range of cancer types, including ovarian cancer. Furthermore, protein levels of Sox 2 and ST6Gal-I were found to strongly correlate in established ovarian cancer cell lines. We next interrogated a possible direct interaction between Sox 2 and ST6Gal-I by performing Chromatin Immunoprecipitation (ChIP) assays, which revealed that Sox2 binds to sequences proximal to the ST6GAL1 P3 promoter. To confirm that Sox2 regulates ST6Gal-I expression, Sox2 was knocked-down in $\mathrm{Pa}-1$ ovarian cancer cells, which have high endogenous ST6Gal-I, or overexpressed in Skov3 ovarian cancer cells, which have relatively low ST6Gal-I expression. Sox 2 knock-down reduced ST6Gal-I mRNA and protein expression, and correspondingly diminished surface $\alpha 2-6$ sialylation, whereas Sox2 overexpression increased ST6Gal-I mRNA and protein, and enhanced surface sialylation. These data suggest that Sox2 is a key transcription factor responsible for upregulating ST6Gal-I expression in ovarian cancer cells.

\section{Materials and methods \\ Cell culture}

Skov-3, Pa-1, OVCAR3, OVCAR4, and OVCAR5 cell lines were obtained from ATCC. A2780 parental cells (IP2) and cisplatin resistant cells (CP20) were generously donated by Dr. Charles Landen (University of Virginia). Cells were grown in RPMI (Skov-3, A2780, OVCAR4) or DMEM (Pa-1, OVCAR5) media containing 10\% fetal bovine serum (FBS, Atlanta Biologicals) and antibiotic/antimycotic supplements (Invitrogen). OVCAR3 cells were grown in RPMI with $20 \% \mathrm{FBS}$ and $0.01 \mathrm{mg} / \mathrm{mL}$ of bovine insulin (Sigma). Normal human astrocytes (NHA, Lonza) were cultured in AGM media, and immortalized neural progenitor cells (NPC, Millipore) were propagated in DMEM/F12 supplemented with EGF, FGF and Gem21 (Gemini Bio-Products). Stable polyclonal cell lines with either forced expression of Sox2 (GeneCopoeia), or shRNA against Sox2 (Sigma), were created by lentiviral transduction followed by puromycin selection. Cells with inducible Sox2 expression were generated using lentivirus harboring a tetracycline-inducible Sox 2 construct (GeneCopoeia) followed by selection with blasticidin. Sox2 expression was induced in this latter cell line with $1 \mu \mathrm{g} / \mathrm{ml}$ doxycycline. In a pilot experiment, dox-induced Sox 2 expression was measured at multiple time points, and based on these data, all further dox treatments were conducted at $96 \mathrm{~h}$. Modulation of Sox 2 expression in these various cell models was confirmed by immunoblotting.

\section{Immunoblotting}

Cells were lysed in RIPA buffer (Thermo Fisher Scientific) containing protease and phosphatase inhibitors (Sigma). 
Protein quantification was performed by BCA assay (Pierce). Lysates were resolved by SDS-PAGE and transferred to polyvinylidene difluoride (PVDF) membrane (Sigma). Blots were blocked in 5\% non-fat dried milk and then incubated with primary antibodies against Sox2 (Cell Signaling, 3579S), ST6Gal-I (R\&D Systems, goat polyclonal, AF5924), or $\beta$-tubulin (AbCam). Blots were subsequently incubated with the appropriate secondary antibody (Cell Signaling, anti-rabbit; R\&D systems, antigoat), and then developed using either Clarity (Bio-Rad) or SuperSignal West Femto (Pierce) enhanced chemiluminescence (ECL) substrates.

\section{mRNA isoform analysis}

RNA was isolated from cells using the Ambion RNA extraction kit (Life Technologies). cDNA was then synthesized according to the vendor protocol (Promega), and PCR was used to amplify specific ST6Gal-I isoforms. Primers with the following sequences were obtained from Integrated DNA Technologies:

H isoform: forward: GTCTCTTATTTTTTGCCT TTGCAG, reverse: CCACACACAGATGACTGCAA YZ isoform: forward: AGTCCAGGGAGAAG TGGTGA, reverse: CCACACACAGATGACTGCAA $\mathrm{X}$ isoform: forward: CTTCTCCCATACCTTGCT CTACA, reverse: GAAGATGTGTTCAGGGAA GTCAC

Coding region: forward: TATCGTAAGCTGCACCCC AATC, reverse: TTAGCAGTGAATGGTCCGGAAG. GAPDH: forward: TGGTATCGTGGAAGGACTCA; reverse: AGTGGGTGTCGCTGTTGAAG.

Isoform-specific PCR products were visualized on a $1.2 \%$ agarose gel with ethidium bromide.

\section{qRT-PCR}

For analyses of ST6Gal-I and Sox2 mRNA expression, TaqMan Fast Master Mix (Thermo Fisher Scientific) was used and primers were purchased from Applied Biosystems: ST6Gal-I (Assay ID: Hs00949382_m1) and Sox2 (AssayID: Hs00602736_m1); mRNA expression was normalized to GAPDH (Assay ID: HS02786624_g1). At least 3 independent experiments were conducted, with each individual experiment performed with 3 technical replicates. Statistical significance was defined as $p<0.05$ based on a Student's T Test.

\section{Chromatin Immunoprecipitation (ChIP)}

Cells were plated at a density of $1 \times 10^{8}$ cells per 150 $\mathrm{cm}^{2}$ dish, and allowed to adhere overnight. Cells were fixed with $3.7 \%$ paraformaldehyde (Thermo Fisher Scientific) for $10 \mathrm{~min}$, and then fixation was stopped by adding $2.5 \mathrm{M}$ glycine. Cells were washed with phosphate- buffered saline (PBS) containing protease inhibitors, removed from the plate using a cell scraper, and centrifuged at $1000 \mathrm{x} \mathrm{g}$ for $5 \mathrm{~min}$. Cell pellets were then resuspended in hypotonic buffer (10 mM HEPES, pH 7.9; $1.5 \mathrm{mM}$ $\mathrm{MgCl}_{2}, 10 \mathrm{mM} \mathrm{KCl}, 2.5 \mathrm{M}$ glycine) with fresh protease inhibitors, and incubated on ice for 5 min. NP-40 (Sigma Aldrich) was added to the solution at a final concentration of $0.5 \%$. Samples were incubated on ice for $5 \mathrm{~min}$. Cells were centrifuged and the pellets resuspended in TE buffer (Thermo Fisher Scientific) with fresh protease inhibitors. Samples were then sonicated using a BioRupter for $20 \mathrm{cy}$ cles of $30 \mathrm{~s}$ on; $30 \mathrm{~s}$ off; with temperature remaining at $4{ }^{\circ} \mathrm{C}$. Following sonication, samples were centrifuged at $4{ }^{\circ} \mathrm{C}$ for $15 \mathrm{~min}$ and cell pellet debris was removed. $5 \%$ of the sample was removed for the input control. A 1:1 volume of 2x RIPA buffer was then added to each sample along with either a ChIP-validated anti-Sox2 antibody (Cell Signaling, 5024S) or a nonspecific IgG control antibody (Cell Signaling, 3900S). Chromatin samples were incubated with the antibodies for $2 \mathrm{~h}$ at $4{ }^{\circ} \mathrm{C}$ with rotation. Samples were then incubated with Protein G dynabeads (Invitrogen) overnight at $4{ }^{\circ} \mathrm{C}$ with rotation. The antibody/ chromatin complexes were collected by placing the samples in a magnet (DynaMag, Life Technologies), and complexes were washed with the following series of buffers at $4{ }^{\circ} \mathrm{C}$ with rotation for 5 min each: Low salt buffer $(0.1 \%$ SDS, $1 \%$ Triton-X-100, $1 \%$ sodium deoxycholate, $1 \mathrm{mM}$ EDTA, $10 \mathrm{mM}$ Tris $\mathrm{HCl}$, pH 8.1); $\underline{\text { High salt buffer }}(0.1 \%$ SDS, $1 \%$ Triton-X-100, $2 \mathrm{mM}$ EDTA, $20 \mathrm{mM}$ Tris $\mathrm{HCl}$, $\mathrm{pH}$ 8.1, $150 \mathrm{mM} \mathrm{NaCl})$, and $\mathrm{LiCl}$ Buffer $(0.25 \mathrm{M} \mathrm{LiCl}, 1 \%$ NP-40, 1\% sodium deoxycholate, $1 \mathrm{M}$ EDTA, $10 \mathrm{mM}$ Tris $\mathrm{HCl}, \mathrm{pH}$ 8.1). Complexes were subsequently washed twice with TE buffer. Following the washes, samples were incubated with fresh elution buffer (10\% SDS, $1 \mathrm{mM} \mathrm{NaHCO}$ ) at room temperature for $15 \mathrm{~min}$; this step was repeated once. Eluates were collected, and crosslinking reversed by adding $0.2 \mathrm{M} \mathrm{NaCl}$ and $10 \mathrm{mg} / \mathrm{mL}$ RNase A (Thermo Fisher Scientific) and incubating at $65^{\circ} \mathrm{C}$ for $4 \mathrm{~h}$. Protein was then degraded by adding proteinase $\mathrm{K}(20 \mathrm{mg} / \mathrm{mL})$ to a final concentration of $50 \mu \mathrm{g} / \mathrm{ml}$ at $60^{\circ} \mathrm{C}$ for $1 \mathrm{~h}$. DNA was purified using the SimpleChIP DNA purification kit (Cell Signaling) according to the manufacturer's instructions. PCR was conducted using the $\mathrm{SYBR}^{\circ} \mathrm{Green}$ system (Thermo Fisher Scientific). Primer sequences for PCR are as follows:

1A: forward: TTGTGGCTGTGATCCTTTCA, reverse: CTGCACAGATGGGCTGATAA; 1B: forward: TGCCCCCACTCTGCTTTATC, reverse: TTTAAGCACACAGGGATGGCT; 2A: forward: GGTTACTCCAGGCTGAGTCG, reverse: CTCCAGGAGGTGAAGGTGAG; 2B: forward: CCGCTTGGGCATCAGACTAA, reverse: CGACTCAGCCTGGAGTAACC; 
3A: forward: GAGGAGGGATTGGGTTTGTT, reverse: TCCTTAAACAGCACAGTTCCA; 3B: forward: ACTGTGCTGTTTAAGGATCAACTG, reverse: AACTGGGCTCCACAATGCAA.

Data were normalized to the percent input, and then values for the nonspecific IgG ChIP were normalized to 1.0 .

\section{Flow Cytometry}

Cells were detached from tissue culture plates with Accutase (Corning) and washed with cold PBS. Cells were blocked in $1 \%$ bovine serum albumin (BSA) in PBS for $30 \mathrm{~min}$ on ice. Cells were stained with Dylight 649conjugated SNA (EY labs), a lectin that specifically binds a2-6 linked sialic acids. Cells were stained with SNA649 at dilutions of 1:200 or 1:400, depending on cell type, in $0.1 \%$ BSA in PBS for 40 min on ice. Binding of SNA-649 was quantified using the LSRII flow cytometer courtesy of the UAB Flow Cytometry Core.

\section{TCGA analyses}

The presence of copy number alterations for ST6GAL1 and SOX2 in human tumor tissues was evaluated in TCGA datasets using cBioportal $[52,53]$. cBioportal was used to obtain a GISTIC score for these two genes across 74 cancer cohorts (the total number of datasets for which copy number data were available). A GISTIC score of +1 or +2 was considered to indicate an amplification (colored red), and a score of -1 or -2 indicates a deletion (colored blue). Percent of alteration was calculated from the percentage of samples in each cohort that contained an amplification or deletion.

\section{Results}

\section{SOX2 and ST6GAL1 are co-amplified in many human} cancers including ovarian cancer

TCGA databases were screened for changes in SOX2 and ST6GAL1 copy number. There were 74 cohorts with available data for copy number alterations, spanning a broad range of cancer types. The 74 cohorts were aligned from left to right based on the prevalence of SOX2 copy number variations (Fig. 1a, upper panel). This same order of cohorts was used to graph the data for ST6GAL1 (lower panel). For example, the first two bars on the left of the graph represent lung squamous cell carcinoma (SCC) cohorts (tan circles), whereas the third bar, marked with an asterisk ("), depicts an ovarian serous carcinoma cohort (light blue circle). Results in Fig. 1a reveal several notable findings. First, both the SOX2 and ST6GAL1 genes are extensively amplified, but rarely deleted, across multiple cancer types. Secondly, in almost every case, SOX2 and ST6GAL1 are amplified together. Among the 50 out of 74 cohorts that display copy number alterations in either SOX2 or ST6GAL1, 48 cohorts had amplification of both genes. A third important finding is that there is a striking similarity between the frequency of SOX2 and ST6GAL1 copy number gains (CNGs) across the cohorts. For instance, the rates of SOX2 and ST6GAL1 CNG within the ovarian serous carcinoma cohort (*) are 27 and $24 \%$, respectively.

The ovarian serous carcinoma cohort (*) was subsequently examined in more detail. This cohort includes specimens from 579 patients. Each individual tumor specimen is represented by a single bar, with red bars indicating patients with CNGs in SOX2 or ST6GAL1 (Fig. 1b). As shown, the great majority of patients harboring SOX2 CNGs also display amplification of ST6GAL1. Statistical analyses indicate a significant cooccurrence of CNGs for these two genes $(p<0.001)$. In fact, significant co-occurrence is found for all of the 48 TCGA cohorts with dual SOX2 and ST6GAL1 amplification.

Having observed coordinate amplification of SOX2 and ST6GAL1 in human tumor tissues, we next examined the copy number status of these genes in the NCI60 panel of established human cancer cell lines. Again, we noted a strong association between cells with high copy numbers of SOX2 and ST6GAL1 (Fig. 1 c). Furthermore, the ovarian cancer cell lines within the NCI-60 panel showed a clear correlation between SOX2 and ST6GAL1 CNGs (Fig. 1 d). Taken together, the data in Fig. 1 suggest that $S O X 2$ is rarely amplified without simultaneous amplification of ST6GAL1. While co-amplification doesn't directly infer a functional relationship between these two genes, these data hint at a selective process whereby amplification of these two genes may be beneficial to the malignancy.

\section{Levels of ST6Gal-I and Sox2 protein are correlated in ovarian cancer cell lines}

We next evaluated levels of Sox 2 and ST6Gal-I protein in multiple ovarian cancer cell lines. Figure 2a depicts immunoblots from the following lines: $\mathrm{Pa}-1$ (derived from an ovarian teratocarcinoma [54]); Skov3 (thought to be a clear cell ovarian cancer line [55, 56]); and OVCAR3 (derived from high-grade serous ovarian adenocarcinoma [57]). Sox2 and ST6Gal-I protein were found to be highly expressed in $\mathrm{Pa}-1$ and OVCAR3 cells, whereas expression of these two proteins was relatively low in Skov3 cells. A similar correspondence in Sox 2 and ST6Gal-I protein levels was observed in additional ovarian cancer cell lines (Fig. 2 b). The OVCAR4 line is one of the few ovarian cancer lines that lacks detectable ST6Gal-I protein (unpublished observation), and Sox2 is likewise undetectable in this line. We also compared Sox2 and 


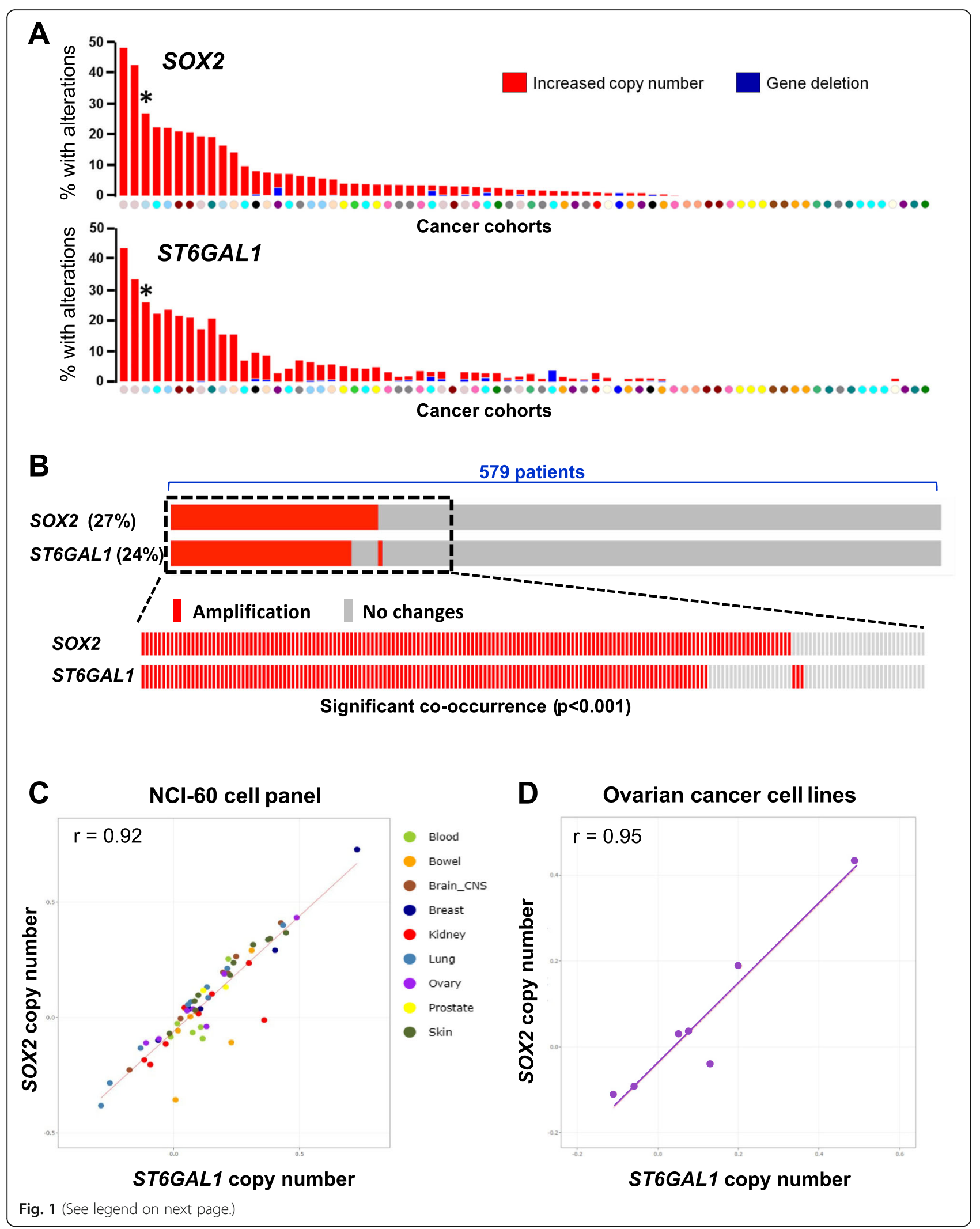


(See figure on previous page.)

Fig. 1 SOX2 and ST6GAL1 co-amplification. a Aligned TCGA datasets showing copy number alterations for SOX2 (upper panel) and ST6GAL1 (lower panel). Colored circles represent the various types of cancer cohorts. The cohorts were ordered based on the frequency SOX2 amplification in the distinct cohorts and the same cohort order was then used to graph the data for ST6GAL1 copy number variations. Gene amplification is shown in red, deletion in blue. An ovarian serous carcinoma cohort is marked by *. b Aligned individual patient tumors from the ovarian serous carcinoma cohort $\left(^{*}\right)$ showing SOX2 and ST6GAL1 co-amplification and co-occurrence. c SOX2 and ST6Gal1 copy number in the NCl-60 series of established cancer cell lines. $\mathbf{d}$ SOX2 and ST6Gal1 copy number in the ovarian cancer lines within the NCl-60 panel

ST6Gal-I expression in the matched, isogenic chemosensitive/chemoresistant A2780 ovarian cancer cell series, specifically, the A2780-IP2 line, which is sensitive to cisplatin, and the A2780-CP20 line, which is cisplatin-resistant. We were interested in this model because we previously observed enhanced ST6Gal-I expression in cisplatin-resistant A2780-CP20 cells [22]. As shown in Fig. 2b, both Sox2 and ST6Gal-I were upregulated in A2780-CP20 cells compared with A2780-IP2 cells. These data are consistent with the known roles of Sox2 and ST6Gal-I in chemoresistance, a phenotypic hallmark of CSCs [25, 58, 59].

In addition to promoting CSC characteristics, Sox 2 and ST6Gal-I have been implicated in the maintenance of stem-like properties in nonmalignant cells [37, 60, 61]. As well, ChIPSeq results point to Sox2 as a regulator of ST6Gal-I expression in stem/progenitor populations [62-64]. To examine the relationship between Sox2 and ST6Gal-I in nonmalignant populations with changes in differentiation status, immunoblotting was conducted on lysates from neural progenitor cells or human astrocytes. As shown in Fig. 2c, levels of Sox2 and ST6Gal-I protein were very high in neural progenitor cells, but undetectable in astrocytes. These data support the concept that, like Sox2, ST6Gal-I expression is enriched in progenitor cells.

\section{Ovarian cancer cells primarily express the P3-driven ST6Gal-I mRNA isoform}

The strong correlation between Sox 2 and ST6Gal-I expression is likely due, at least in part, to the coordinate amplification of these two genes in cancer cells. However, in addition to this mechanism, a ChIP study suggested that Sox 2 may regulate ST6Gal-I transcription [38]. Hence, we investigated whether Sox 2 binds to the ST6GAL1 promoter. To address this hypothesis, we first determined which ST6GAL1 promoter was the primary driver of ST6Gal-I expression in ovarian cancer cells. The schematic diagram in Fig. 3a depicts three of the major ST6Gal-I mRNA isoforms. The "YZ" form, which encompasses exons $\mathrm{Y}$ and $\mathrm{Z}$, is driven by the P3 promoter. The " $\mathrm{X}$ " form is driven by the $\mathrm{P} 2$ promoter, whereas the " $\mathrm{H}$ " form is driven by $\mathrm{P} 1$. While each isoform contains its own unique transcriptional start site (TSS) and $5^{\prime}$ untranslated region, the coding region, included within exons II-VI, is conserved. Primers were developed for each of the isoforms, as indicated in Fig. $3 \mathrm{a}$, with the $5^{\prime}$ (forward) primer denoted as " $\mathrm{f}$ " and the 3' (reverse) primer denoted as "r." Expression of the isoforms was assessed in four ovarian cancer cell lines by RT-PCR, followed by gel electrophoresis. As shown in Fig. 3b, the P3-driven YZ variant was the major isoform noted in all of the cell lines (the coding region was also amplified as a positive control).
A

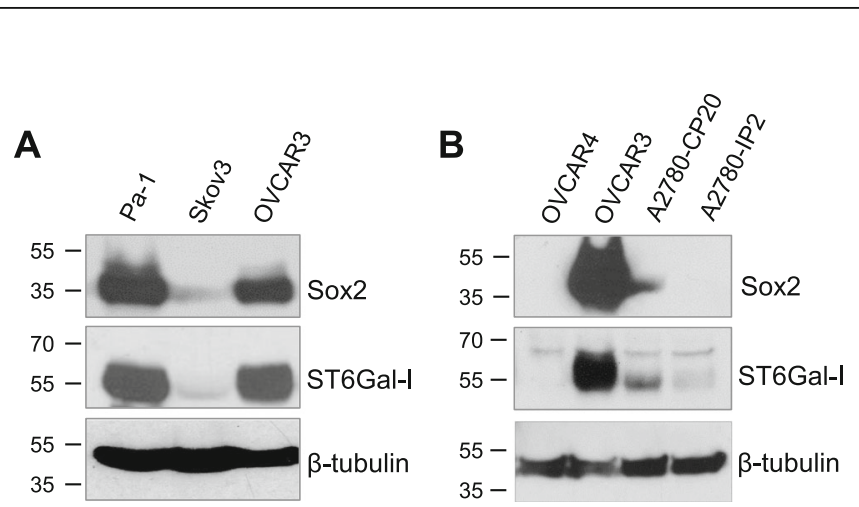

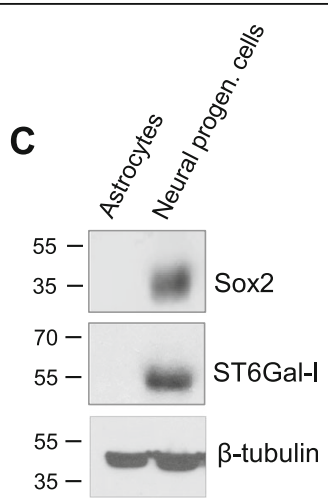

Fig. 2 Sox2 and ST6Gal-I expression levels correspond in ovarian cancer cell lines. Immunoblots for ST6Gal-I and Sox2 expression in: a ovarian cancer cell lines, Pa-1, Skov-3, and OVCAR3; b ovarian cancer cell lines, OVCAR 4, OVCAR3, A2780-CP20 (cisplatin-resistant), and A2780-IP2 (cisplatin-sensitive); and $\mathbf{c}$ normal human astrocytes and neural progenitor cells 


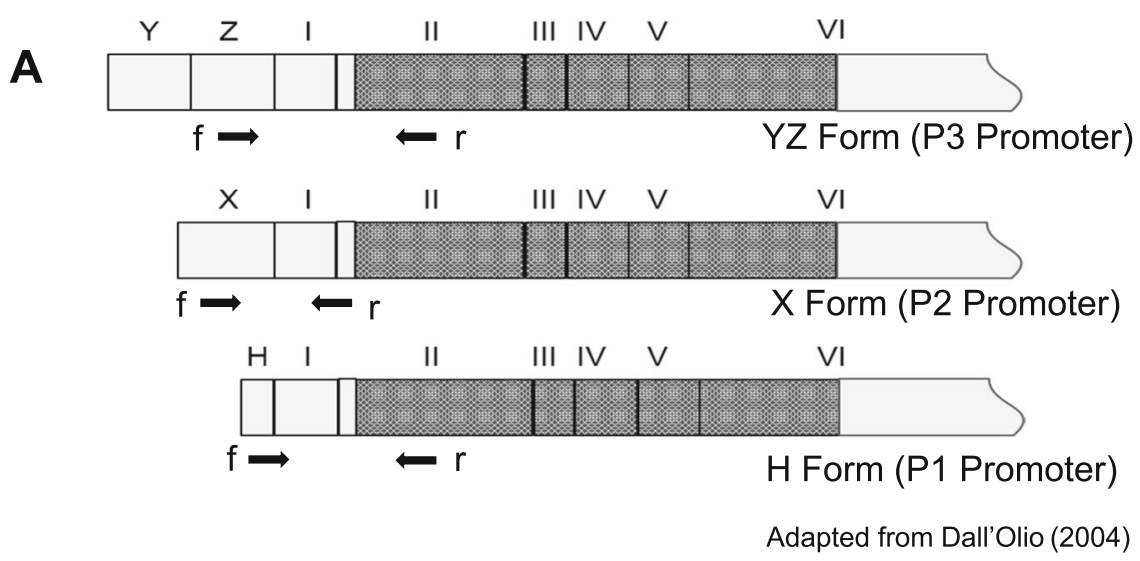

B

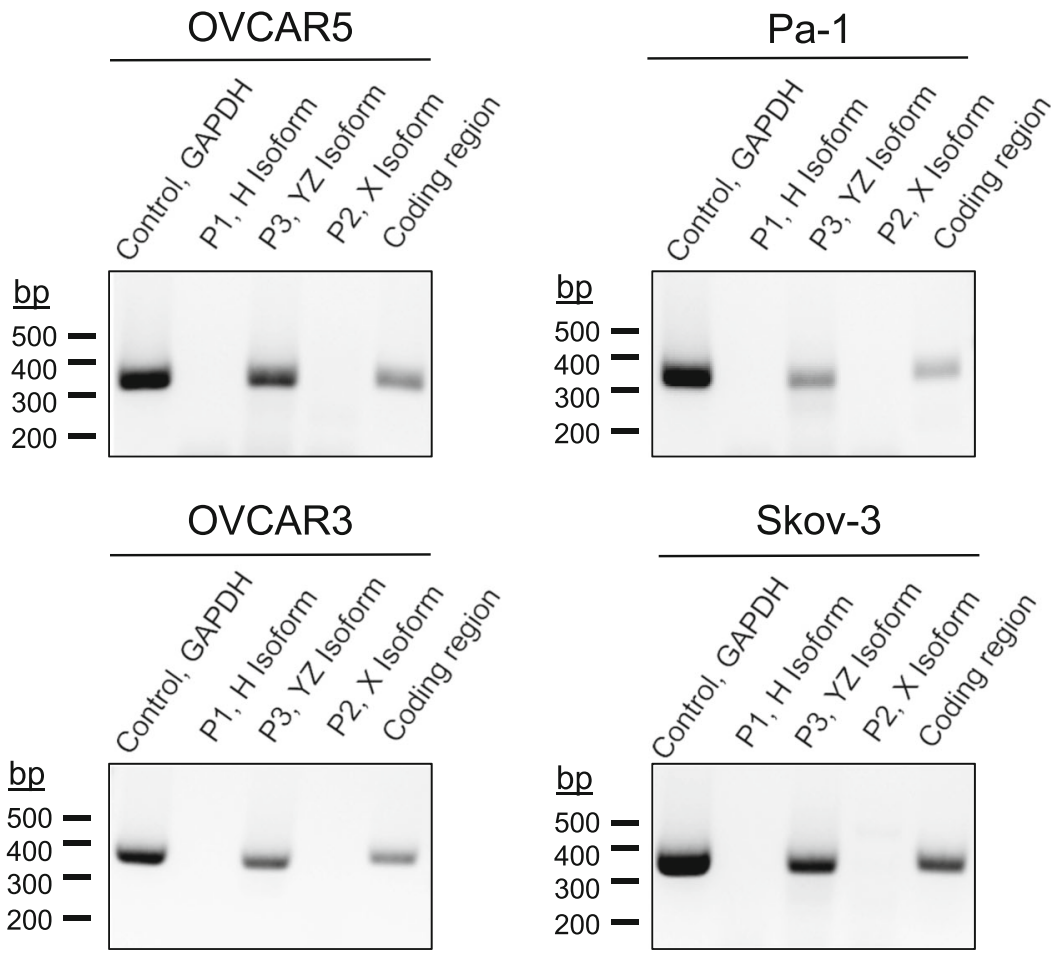

Fig. 3 ST6Gal-I expression is driven primarily by the P3 promoter. a Graphical representation of the 3 promoter-specific mRNA isoforms of ST6GalI (adapted from Dall'Olio et al. [26]). Shaded region indicates the coding sequence, which begins in Exon II and spans through part of Exon VI. $\mathbf{b}$ ST6Gal-I mRNA isoforms were amplified by PCR using isoform-specific primers. The PCR products were resolved on agarose gels, and detected with ethidium bromide. The expected sizes for the PCR products are $284 \mathrm{bp}$ for the $\mathrm{H}$ form, $363 \mathrm{bp}$ for the YZ form, and $253 \mathrm{bp}$ for the X form. We also performed PCR with primers for the ST6Gal-I coding region (expected product $=372$ bp), along with primers for GAPDH as a control (expected product $=371 \mathrm{bp}$ )

Sox2 binds directly to sites proximal to the ST6GAL1 P3 promoter

ChIP assays were conducted to determine whether Sox2 binds to the ST6GAL1 P3 promoter. The Pa-1 cell line was used as a model due to its high expression of Sox2. Prior to performing ChIP assays, we validated the anti-Sox2 ChIP antibody. The anti-Sox2 antibody and a nonspecific IgG control were incubated with chromatin preparations harvested from $\mathrm{Pa}-1$ cells, and the immunoprecipitates were evaluated for Sox 2 by immunoblotting. As shown in Fig. 4a, Sox2 was detected in anti-Sox2 immunoprecipitates, but not in control IgG samples. We then utilized the Gene Transcription Regulation Database (GTRD [65]), to identify ChIP-seq-verified Sox2 binding sites on the ST6GAL1 gene. We focused on three known Sox2 binding 


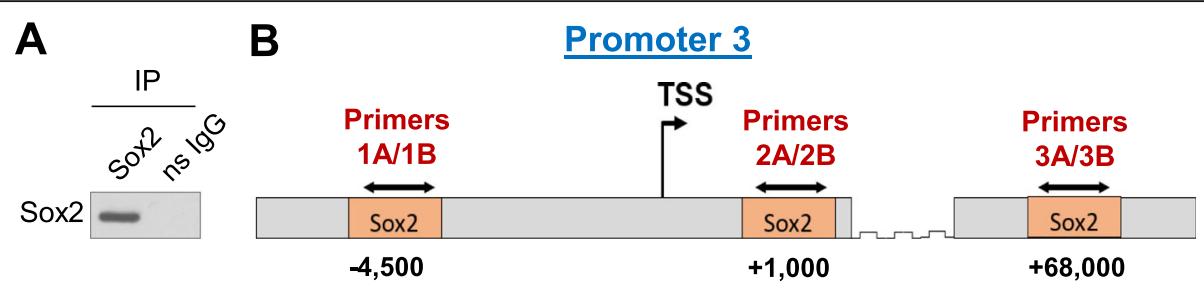

C

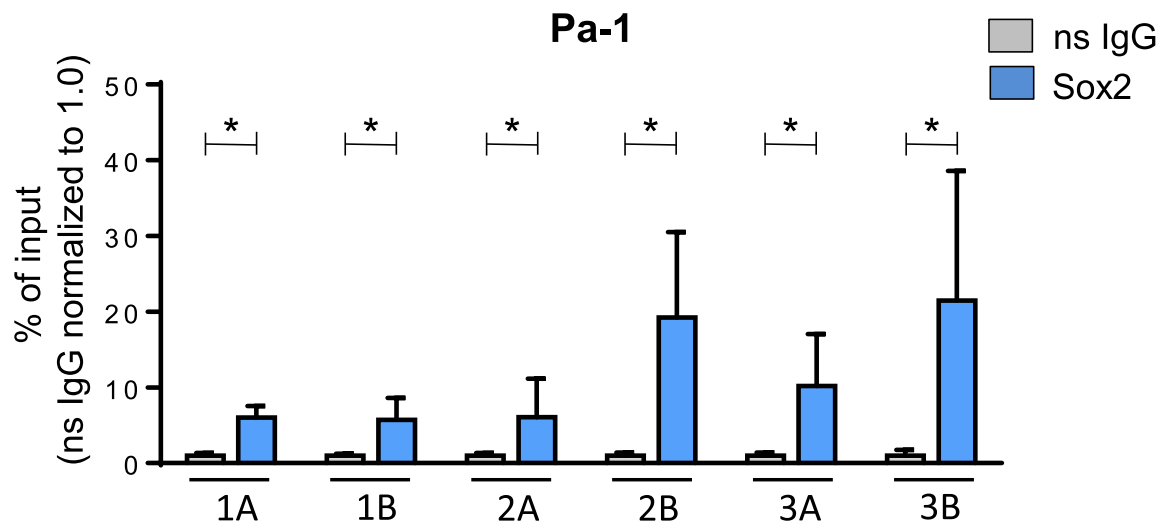

Fig. 4 Sox2 binds to multiple regions within the ST6GAL1 gene. a Immunoblot verification of Sox2 immunoprecipitation by the ChIP-validated anti-Sox2 antibody. $\mathbf{b}$ Schematic depicting three known Sox2-binding elements within the ST6GAL1 gene (positioned at $-4500,+1000$, and + 68,000 relative to the TSS within the P3 promoter). Primers $1 \mathrm{~A}$ and $1 \mathrm{~B}$ were designed to flank the -4500 site, Primers $2 \mathrm{~A}$ and $2 \mathrm{~B}$ flank the +1000 site, and Primers $3 \mathrm{~A}$ and $3 \mathrm{~B}$ flank the $+68,000$ site. c ChIP assays conducted in Pa-1 ovarian cancer cells show that Sox2 binds all three of the predicted Sox2-binding elements within STGGAL1. * denotes $p<0.05$

elements, a site $\sim 4500$ bp upstream of the P3 TSS; a site $\sim 1000$ bp downstream of the TSS, and a site at $\sim$ $68,000 \mathrm{bp}$ downstream of the TSS. While the $+68,000$ Sox2 binding element lies within an intron between exons $\mathrm{Z}$ and $\mathrm{I}$, recent evidence has underscored an important function for Sox in regulating gene transcription through its binding to distal enhancers [66-68]. To examine Sox 2 binding, two distinct sets of primers were designed to flank each of the three binding sites: primers $1 \mathrm{~A}$ and $1 \mathrm{~B}$ for the $-4500 \mathrm{bp}$ site; primers $2 \mathrm{~A}$ and $2 \mathrm{~B}$ for the $+1000 \mathrm{bp}$ site; and primers $3 \mathrm{~A}$ and $3 \mathrm{~B}$, which bind the $+68,000 \mathrm{bp}$ site (schematic diagram in Fig. 4 b). ChIP experiments were then conducted on $\mathrm{Pa}-1$ cells, and primer binding was quantified by qRTPCR, with results normalized to input values. As shown in Fig. 4c, significant differences were found between the Sox 2 and nonspecific IgG samples for all primer sets, suggesting that Sox 2 binds to each of the three ChIP-seq-verified response elements.

\section{Direct modulation of Sox2 expression alters ST6Gal-I expression and cell surface sialylation}

To substantiate a role for Sox2 in regulating ST6Gal-I expression, we modulated Sox 2 expression in ovarian cancer cells, and then measured ST6Gal-I mRNA and protein. Sox 2 was knocked-down (KD) in the Pa-1 line, given that these cells have high Sox2 expression, and overexpressed (OE) in Skov3 cells, which have relatively low Sox2 expression. Sox 2 mRNA levels were evaluated by qRT-PCR to verify successful KD (Fig. 5 a) or OE (Fig. 5 b). We also created a Skov3 line with doxycycline (dox)-inducible Sox 2 expression. A pilot time course experiment suggested that a $96 \mathrm{~h}$ dox treatment was optimal for inducing Sox 2 expression (Fig. 5 c). Further experiments using the $96 \mathrm{~h}$ time point confirmed that dox treatment significantly increased Sox 2 levels (Fig. 5 d).

Cells were then evaluated for ST6Gal-I mRNA expression. Sox $2 \mathrm{KD}$ in Pa-1 cells decreased the expression of ST6Gal-I mRNA (Fig. 5 e), while both constitutive (Fig. 5 f), and inducible (Fig. 5 g), Sox2 OE in Skov3 cells upregulated ST6Gal-I mRNA. These data were validated by immunoblotting experiments, which showed that Sox2 KD inhibits, while Sox2 OE enhances, expression of ST6Gal-I protein (Fig. 5 h-j). Finally, the surface $\alpha 2-6$ sialylation of cells with modulated Sox 2 expression was examined as a measure of ST6Gal-I activity. To this end, cells were stained with SNA, a lectin specific for $\alpha 2-6$ sialic acids, and analyzed by flow cytometry. In Pa- 1 cells with Sox 2 KD, we observed decreased surface $\alpha 2-6$ sialylation (Fig. $5 \mathrm{k}$ ) whereas $\alpha 2-6$ sialylation was enriched in both the constitutive and inducible Sox 2 OE models (Fig. L-M). In the aggregate, these data suggest that Sox2 directly promotes the expression of ST6Gal-I in ovarian cancer cells, leading to enhanced surface $\alpha 2-6$ sialylation. 


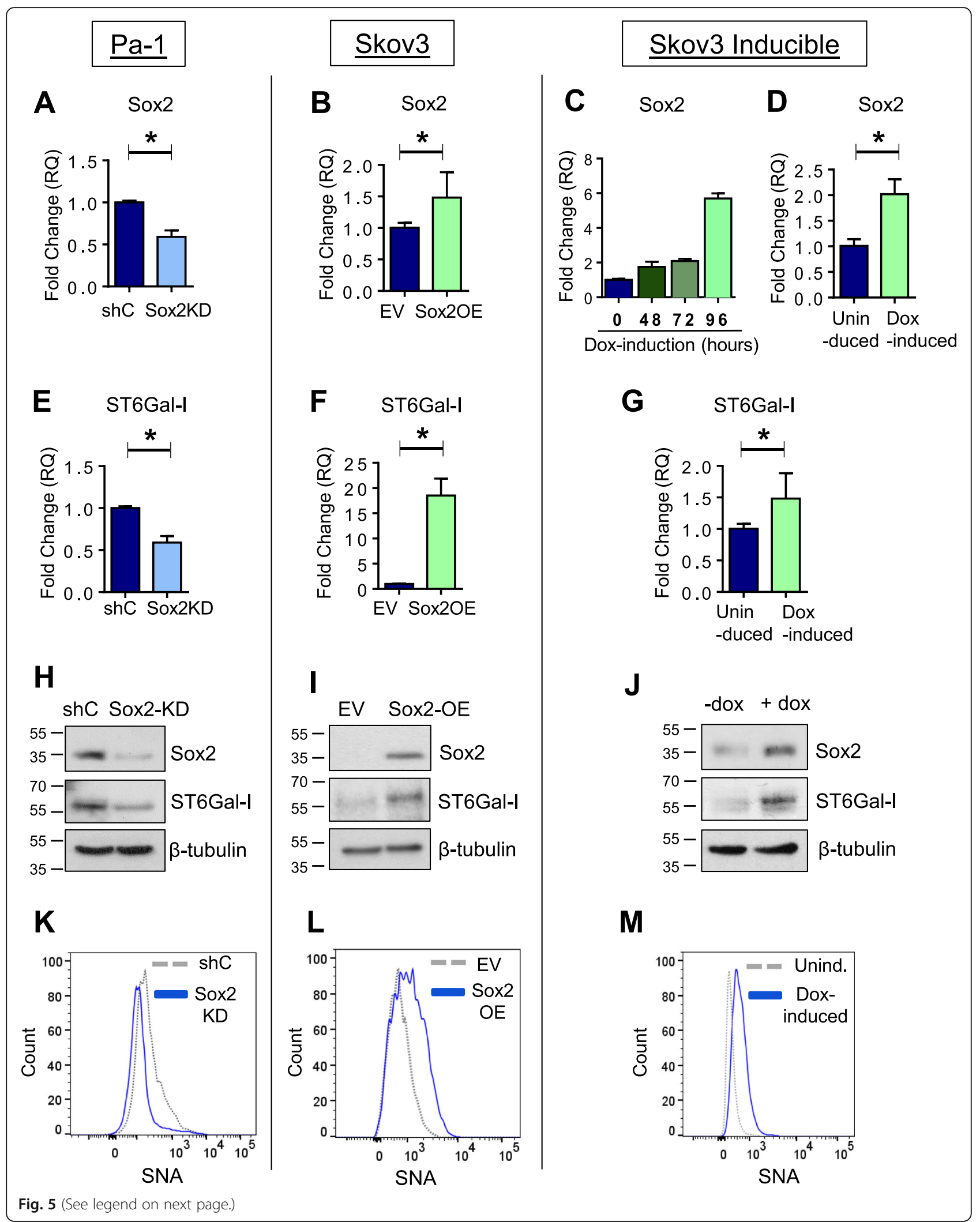


(See figure on previous page.)

Fig. 5 Sox2 promotes expression of ST6Gal-I mRNA and protein, leading to enhanced surface a2-6 sialylation. a Sox2 mRNA expression in Pa-1 cells with Sox2 knockdown (KD) or cells transduced with a control shRNA (shC). b Skov3 cells with forced overexpression (OE) of Sox2 or cells transduced with a control empty vector (EV). c Skov3 cell line with doxycycline (dox)-inducible expression of Sox2. Cells were treated with dox for a time course of 48,72 , or 96 h. $\mathbf{d}$ Sox 2 mRNA expression in cells with inducible Sox2 OE; cells were either induced for $96 \mathrm{~h}$ or left uninduced. e ST6Gal-I mRNA expression in Pa-1 shC and KD cells. $\mathbf{f}$ ST6Gal-I mRNA expression in Skov3 EV and OE cells. g ST6Gal-I mRNA expression in Skov3 cells with inducible Sox2. Cells were either left uninduced or treated with dox for $96 \mathbf{h}$. h-j Immunoblot for Sox2 and ST6Gal-I in Pa-1 shC and KD cells (h), Skov3 EV and OE cells (i), or Skov3 inducible cells treated with or without dox treatment for $96 \mathbf{h}$ (j). $\mathbf{k}-\mathbf{m}$. SNA staining to detect a2-6 surface sialylation in Pa-1 shC and KD cells (k), Skov-3 EV and OE cells (I), and Skov-3 inducible cells with or without dox treatment for $96 \mathrm{~h}$ (m). * denotes $p<0.05$

\section{Discussion}

A plethora of literature has established Sox2 as a master regulator of stemness. Sox 2 plays a seminal part in balancing the transcription of genes that regulate a cell's differentiation state $[43,60,69,70]$. Following the discovery that genetic deletion of Sox 2 is embryonic lethal, research has focused on the importance of Sox 2 in cell fate determination and stem cell maintenance [61, 71, 72]. However, another crucial function for Sox 2 has recently emerged: its role in cancer development and promotion of CSCs characteristics [45, 46, 73]. Sox2 activity propels tumor cell migration and invasion [74], selfrenewal [45], tumor initiating capacity [47], and chemoresistance [70]. Interestingly, these same CSC features are imparted by ST6Gal-I [9, 12, 16, 22, 25]. In addition to shared functionality, there is evidence suggesting that Sox2 and ST6Gal-I mRNA levels are correlated [38-40], and that ST6Gal-I may, in fact, act as a downstream effector of Sox2 to promote stemness. As an example, Wang et al. showed that knock-down of ST6Gal-I suppressed the transition to pluripotency induced by the four Yamanaka factors, one of which is Sox2 [37]. These findings implicate an interplay between Sox2 and ST6Gal-I that may be crucial for maintaining the cellular properties necessary to support a progenitor-like state.

While an association between Sox2 and ST6Gal-I mRNA levels has been noted previously [38-40], results herein show that Sox2 and ST6Gal-I expression at the protein level is correlated across multiple ovarian cancer cell lines. One potential reason for this correlative expression is that the SOX2 and ST6GAL1 genes lie within the same amplicon, 3q26, and are coordinately amplified in the vast majority of tumor specimens. Likewise, there is a strong correspondence between SOX2 and ST6GAL1 CNGs in the NCI-60 panel of established cancer cell lines. The 3q26 amplicon is one of the most pervasively amplified chromosomal regions in cancer, and is known for promoting stem-like cancer cell characteristics [48]. This particular amplicon is estimated to occur in greater than $20 \%$ of all human cancers [48], with amplification rates as high as $75 \%$ in invasive lung SCC [75], and between 25 and $30 \%$ in ovarian cancer [51, 76, 77]. In addition to lung SCC and ovarian cancer, 3q26 amplification has been documented in esophageal SCC, head and neck SCC, and cervical cancer [49, 50, 78-80]. The most widely studied genes within $3 \mathrm{q} 26$ include $S O X 2$, PRKCI, ECT2, and PIK3CA, and these genes work together to promote carcinogenesis [80]. Of note, 3q26 amplification is an early event in tumorigenesis, which aligns with evidence suggesting that Sox2 functions as an initiating oncogene in ovarian cancer [42, 80, 81]. However, while extensive research has focused on SOX2, the presence of ST6GAL1 within the 3q26 amplicon has escaped attention. We postulate that some of the tumorpromoting activity of the 3q26 amplicon may be mediated by ST6GAL1.

In conjunction with genetic co-amplification, Sox2 may directly regulate the expression of ST6Gal-I. Our analyses of publically available ChIPSeq databases uncovered two Sox2 binding elements proximal to the ST6GAL1 P3 promoter, one at $\sim 4500$ bp upstream, and another $\sim 1000$ downstream, of the TSS. A third site was identified at $\sim 68,000 \mathrm{bp}$ downstream of the P3 TSS, an area that lies within an intron between exons $\mathrm{Z}$ and $\mathrm{I}$. Using ChIP assays, we confirmed Sox2 binding to all three of these sites in ovarian cancer cells. These data are noteworthy because prior ChIPSeq experiments were conducted primarily in stem cell models, or other types of cancers. More specifically, ChIPSeq databases show that Sox 2 binds to the $\sim 4500 \mathrm{bp}$ site upstream of the TSS in ESC-derived neural progenitor cells (NPCs) [62], whereas the +1000 bp site is bound by Sox 2 in NPCs, ESCs, and iPSCs [62-64, 82]. Sox2 similarly associates with the $1000+$ bp site in select cancer cell populations such as thyroid gland medullary carcinoma and esophageal SCC [64] The third site at $\sim 68,000$ bp downstream of the TSS is bound by Sox 2 in ESCs and iPSCs [62, 63, 82-84]. Intriguingly, this latter site is in close proximity to Oct4 and Nanog binding sites [82, 84]. These findings, combined with our own, suggest that Sox2 regulates ST6Gal-I expression in a variety of stem and cancer cell populations.

We further established that Sox2 promotes ST6Gal-I expression by modulating Sox2 levels and examining ST6Gal-I mRNA and protein. While Sox2-induced ST6Gal-I protein expression has not been previously reported, other groups have described Sox2-mediated changes in ST6Gal-I mRNA. In a glioblastoma (GBM) 
model focused on the regulation of cell plasticity, Berezovsky et al. found that knock-down of Sox 2 resulted in a 3.9 fold decrease in ST6Gal-I mRNA; this study also revealed that Sox2 was essential for the maintenance of GBM CSCs [40]. Zhu et al. investigated Sox2 as a marker for stem-like bladder cancer cells and determined that overexpression of Sox 2 induced an increase in ST6Gal-I mRNA [39]. A third group evaluated Sox2 in the context of SCC of the skin [38]. Sox2 knock-in mice with SCC had elevated mRNA levels of ST6Gal-I whereas ST6Gal-I mRNA was reduced in Sox2 knockout mice [38]. While these studies support a correlation between Sox2 and ST6Gal-I, our study provides an advance by showing that Sox2 activity leads to enhanced protein expression and importantly, increased cell surface $\alpha 2-6$ sialylation. It is well known that the phenotypic effects of ST6Gal-I are directed by enriched receptor sialylation, which correspondingly modulates intracellular signaling networks [11-13].

The dearth of information regarding mechanisms that mediate differential ST6Gal-I expression in diverse cell types represents a major gap in the field. In particular, very little is known about ST6Gal-I regulation in stem and progenitor cells. On the other hand, there is some insight into pathways that induce ST6Gal-I expression in cancer cells. Several groups, including ours, have shown that ST6Gal-I is upregulated in response to signaling by oncogenic ras $[27,85,86]$. Piller's group further determined that activated ras acts through RalGEF to promote expression of the P3-driven ST6Gal-I isoform [27]. ST6Gal-I has also been identified as part of a BRAF-driven metastatic gene signature in melanoma [87]. Moreover, ST6Gal-I is upregulated via SP-1dependent transcription during TGF $\beta$-induced epithelial to mesenchymal transition in breast cancer cells [88]. Finally, cytokines typically present within the tumor microenvironment, such as TNF, IL-1, and IL-6, have been shown to increase ST6Gal-I expression [89, 90]. The current study adds to the body of literature by highlighting a novel role for Sox 2 in promoting expression of ST6Gal-I in ovarian cancer cells.

\section{Conclusions}

Studies herein describe a complex relationship between Sox2 and ST6Gal-I. Both genes are commonly amplified in cancer cells due to their shared presence within the $3 \mathrm{q} 26$ amplicon, and then the transcribed Sox 2 protein binds the ST6GAL1 promoter to further enhance ST6Gal-I expression. These collective events may contribute to the remodeling of cancer cells into a more stem-like cell phenotype.

\section{Authors' contributions}

$K A D, R B J$ and KEA were responsible for the acquisition and analysis of the data. $\mathrm{ABH}$ provided reagents, and also contributed to data analysis. KAD,
$\mathrm{ABH}$ and SLB were responsible for the concept and design of this study, and together wrote the manuscript. All authors read and approved the final manuscript.

\section{Funding}

This work was funded by National Institutes of Health grants R01 CA225177 (SLB) and R01 NS104339 (ABH). The authors also acknowledge assistance from the University of Alabama at Birmingham Flow Cytometry Core Facility (supported by National Institutes of Health grants P30AR048311 and P30Al027767)

\section{Availability of data and materials}

All data generated and analyzed during the course of this study are either included in this manuscript, or available through The Cancer Genome Atlas website (https://www.cancer.gov/about-nci/organization/ccg/research/ structural-genomics/tcga).

Ethics approval and consent to participate

Not applicable.

\section{Consent for publication}

Not applicable.

\section{Competing interests}

The authors declare that they have no competing interests.

Received: 31 July 2019 Accepted: 25 September 2019

Published online: 14 October 2019

References

1. Salomon-Perzynski A, Salomon-Perzynska M, Michalski B, Skrzypulec-Plinta V. High-grade serous ovarian cancer: the clone wars. Arch Gynecol Obstet. 2017;295(3):569-76.

2. Cornelison R, Llaneza DC, Landen CN. Emerging therapeutics to overcome Chemoresistance in epithelial ovarian Cancer: a mini-review. Int J Mol Sci. 2017;18(10):2171.

3. Bapat SA, Mali AM, Koppikar CB, Kurrey NK. Stem and progenitor-like cells contribute to the aggressive behavior of human epithelial ovarian cancer. Cancer Res. 2005;65(8):3025-9.

4. Nunes SC, Ramos C, Lopes-Coelho F, Sequeira CO, Silva F, GouveiaFernandes $S$, et al. Cysteine allows ovarian cancer cells to adapt to hypoxia and to escape from carboplatin cytotoxicity. Sci Rep. 2018;8(1):9513.

5. Schultz MJ, Swindall AF, Bellis SL. Regulation of the metastatic cell phenotype by sialylated glycans. Cancer Metastasis Rev. 2012;31(3-4): 501-18.

6. Lu J, Gu J. Significance of beta-Galactoside alpha2,6 Sialyltranferase 1 in cancers. Molecules. 2015;20(5):7509-27.

7. Garnham R, Scott E, Livermore KE, Munkley J. ST6GAL1: a key player in cancer. Oncol Lett. 2019;18(2):983-9.

8. Harduin-Lepers A, Krzewinski-Recchi MA, Colomb F, Foulquier F, GrouxDegroote S, Delannoy P. Sialyltransferases functions in cancers. Front Biosci (Elite Ed). 2012:4:499-515.

9. Schultz MJ, Holdbrooks AT, Chakraborty A, Grizzle WE, Landen CN, Buchsbaum DJ, et al. The tumor-associated Glycosyltransferase ST6Gal-I regulates stem cell transcription factors and confers a Cancer stem cell phenotype. Cancer Res. 2016;76(13):3978-88.

10. Wichert B, Milde-Langosch K, Galatenko V, Schmalfeldt B, Oliveira-Ferrer L. Prognostic role of the sialyltransferase ST6GAL1 in ovarian cancer. Glycobiology. 2018:28(11):898-903.

11. Swindall AF, Bellis SL. Sialylation of the Fas death receptor by ST6Gal-I provides protection against Fas-mediated apoptosis in colon carcinoma cells. J Biol Chem. 2011;286(26):22982-90.

12. Britain CM, Holdbrooks AT, Anderson JC, Willey CD, Bellis SL. Sialylation of EGFR by the ST6Gal-I sialyltransferase promotes EGFR activation and resistance to gefitinib-mediated cell death. J Ovarian Res. 2018;11(1):12.

13. Holdbrooks AT, Britain CM, Bellis SL. ST6Gal-I sialyltransferase promotes tumor necrosis factor (TNF)-mediated cancer cell survival via sialylation of the TNF receptor 1 (TNFR1) death receptor. J Biol Chem. 2018;293(5): $1610-22$.

14. Liu N, Zhu M, Linhai Y, Song Y, Gui X, Tan G, Li J, Liu Y, Deng Z, Chen X, Wang J, Jia L, He X, Wang X, Lin S. Increasing HER2 alpha2,6 sialylation 
facilitates gastric cancer progression and resistance via the Akt and ERK pathways. Oncol Rep. 2018;40(5):2997-3005.

15. Qian J. Zhu, C. H., Tang, S., Shen, A. J., Ai, J., Li, J., Geng, M. Y., Ding, J. alpha2,6-hyposialylation of c-met abolishes cell motility of ST6Gal-Iknockdown HCT116 cells. Acta Pharmacol Sin. 2009;30(7):1039-45.

16. Christie DR, Shaikh FM, Lucas JA, Lucas JA 3rd, Bellis SL. ST6Gal-I expression in ovarian cancer cells promotes an invasive phenotype by altering integrin glycosylation and function. J Ovarian Res. 2008;1 (1):3.

17. Seales EC, Jurado GA, Brunson BA, Wakefield JK, Frost AR, Bellis SL. Hypersialylation of beta1 integrins, observed in colon adenocarcinoma, may contribute to cancer progression by up-regulating cell motility. Cancer Res. 2005;65(11):4645-52.

18. Swindall AF, Londono-Joshi Al, Schultz MJ, Fineberg N, Buchsbaum DJ, Bellis SL. ST6Gal-I protein expression is upregulated in human epithelial tumors and correlates with stem cell markers in normal tissues and colon cancer cell lines. Cancer Res. 2013;73(7):2368-78.

19. Zhu Y, Srivatana U, Ullah A, Gagneja H, Berenson CS, Lance P. Suppression of a sialyltransferase by antisense DNA reduces invasiveness of human colon cancer cells in vitro. Biochim Biophys Acta. 2001;1536(2-3):148-60.

20. Cui H, Yang S, Jiang Y, Li C, Zhao Y, Shi Y, Hao Y, Qian F, Tang B, Yu P. The glycosyltransferase ST6Gal-I is enriched in cancer stem-like cells in colorectal carcinoma and contributes to their chemo-resistance. Clin Transl Oncol. 2018;20(9):1175-84.

21. Jones RB, Dorsett KA, Hjelmeland AB, Bellis SL. The ST6Gal-I sialyltransferase protects tumor cells against hypoxia by enhancing HIF-1alpha signaling. J Biol Chem. 2018;293(15):5659-67.

22. Schultz MJ, Swindall AF, Wright JW, Sztul ES, Landen CN, Bellis SL. ST6Gal-I sialyltransferase confers cisplatin resistance in ovarian tumor cells. J Ovarian Res. 2013;6(1):25.

23. Chen X, Wang L, Zhao Y, Yuan S, Wu Q, Zhu X, Niang B, Wang S, Zhang J. ST6Gal-I modulates docetaxel sensitivity in human hepatocarcinoma cells via the p38 MAPK/caspase pathway. Oncotarget. 2016;7(32):51955-64.

24. Lee M, Park JJ, Ko YG, Lee YS. Cleavage of ST6Gal I by radiation-induced BACE1 inhibits golgi-anchored ST6Gal I-mediated sialylation of integrin beta1 and migration in colon cancer cells. Radiat Oncol. 2012;7:47.

25. Chakraborty A. Dorsett, K. a., Trummell, H. Q., Yang, E. S., Oliver, P. G., Bonner, J. a., Buchsbaum, D. J., Bellis, S. L. ST6Gal-I sialyltransferase promotes chemoresistance in pancreatic ductal adenocarcinoma by abrogating gemcitabine-mediated DNA damage. J Biol Chem. 2017;293(3):984-94.

26. Dall'Olio F. Chiricolo, M., D'Errico, a., Gruppioni, E., Altimari, a., Fiorentino, M., Grigioni, W. F. expression of beta-galactoside alpha2,6 sialyltransferase and of alpha2,6-sialylated glycoconjugates in normal human liver, hepatocarcinoma, and cirrhosis. Glycobiology. 2004;14(1):39-49.

27. Dalziel M, Dall'Olio F, Mungul A, Piller V, Piller F. Ras oncogene induces beta-galactoside alpha2,6-sialyltransferase (ST6Gal I) via a RalGEF-mediated signal to its housekeeping promoter. Eur J Biochem. 2004;271(18):3623-34.

28. Wang X, O'Hanlon TP, Young RF, Lau JT. Rat beta-galactoside alpha 2,6sialyltransferase genomic organization: alternate promoters direct the synthesis of liver and kidney transcripts. Glycobiology. 1990;1 (1):25-31.

29. Wang PH. Lee, W. L., Lee, Y. R., Juang, C. M., Chen, Y. J., Chao, H. T., Tsai, Y. C. , Yuan, C. C. enhanced expression of alpha 2,6-sialyltransferase ST6Gal I in cervical squamous cell carcinoma. Gynecol Oncol. 2003;89(3):395-401.

30. Mifflores-Flores L, Millan-Perez L, Santos-Lopez G, Reyes-Leyva J, Vallejo-Ruiz V. Characterization of P1 promoter activity of the beta-galactoside alpha2,6sialyltransferase I gene (siat 1) in cervical and hepatic cancer cell lines. J Biosci. 2012;37(2):259-67.

31. Dalziel M, Huang RY, Dall'Olio F, Morris JR, Taylor-Papadimitriou J, Lau JT. Mouse ST6Gal sialyltransferase gene expression during mammary gland lactation. Glycobiology. 2001;11(5):407-12.

32. Lo NW, Lau JT. Transcription of the beta-galactoside alpha 2,6sialyltransferase gene in B lymphocytes is directed by a separate and distinct promoter. Glycobiology. 1996;6(3):271-9.

33. Xu L, Kurusu Y, Takizawa K, Tanaka J, Matsumoto K, Taniguchi A Transcriptional regulation of human beta-galactoside alpha2,6sialyltransferase (hST6Gal I) gene in colon adenocarcinoma cell line. Biochem Biophy Res Co. 2003;307(4):1070-4.

34. Rivera-Juarez Mde L, Rosas-Murrieta NH, Mendieta-Carmona V, Hernandez Pacheco RE, Zamora-Ginez I, Rodea-Avila C, Apresa-Garcia T, Garay-Villar O, Aguilar-Lemarroy A, Jave-Suarez LF, Diaz-Orea MA, Milflores-Flores L, Reyes Salinas JS, Ceja-Utrera FJ, Vazquez-Zamora VJ, Vargas Maldonado T, ReyesCarmona S, Sosa-Jurado F, Santos-Lopez G, Reyes-Leyva J, Vallejo-Ruiz V.
Promoter polymorphisms of ST3GAL4 and ST6GAL1 genes and associations with risk of premalignant and malignant lesions of the cervix. Asian Pac J Cancer P. 2014;15(3):1181-6.

35. Dall'Olio F, Chiricolo M, Ceccarelli C, Minni F, Marrano D, Santini D. Betagalactoside alpha2,6 sialyltransferase in human colon cancer: contribution of multiple transcripts to regulation of enzyme activity and reactivity with Sambucus nigra agglutinin. Int J Cancer. 2000;88(1):58-65.

36. Hasehira K, Tateno H, Onuma Y, Ito Y, Asashima M, Hirabayashi J. Structural and quantitative evidence for dynamic glycome shift on production of induced pluripotent stem cells. Mol Cell Proteomics. 2012;11(12):1913-23.

37. Wang YC, Stein JW, Lynch CL, Tran HT, Lee CY, Coleman R, Hatch A, Antontsev VG, Chy HS, O'Brien CM, Murthy SK, Laslett AL, Peterson SE, Loring JF. Glycosyltransferase ST6GAL1 contributes to the regulation of pluripotency in human pluripotent stem cells. Sci Rep. 2015;5:13317.

38. Boumahdi S, Driessens G, Lapouge G, Rorive S, Nassar D, Le Mercier M, Delatte B, Caauwe A, Lenglez S, Nkusi E, Brohee S, Salmon I, Dubois C, del Marmol V, Fuks F, Beck B, Blanpain C. SOX2 controls tumour initiation and cancer stem-cell functions in squamous-cell carcinoma. Nature. 2014; 511(7508):246-50

39. Zhu F, Qian W, Zhang H, Liang Y, Wu M, Zhang Y, Zhang X, Gao Q, Li Y SOX2 is a marker for stem-like tumor cells in bladder Cancer. Stem Cell Reports. 2017;9(2):429-37.

40. Berezovsky AD. Poisson, L. M., Cherba, D., Webb, C. P., Transou, A. D., Lemke, N. W., Hong, X., Hasselbach, L. a., Irtenkauf, S. M., Mikkelsen, T., deCarvalho, A. C. Sox2 promotes malignancy in glioblastoma by regulating plasticity and astrocytic differentiation. Neoplasia. 2014;16(3):193-206 e19-25.

41. Ye F, Li Y, Hu Y, Zhou C, Hu Y, Chen H. Expression of Sox2 in human ovarian epithelial carcinoma. J Cancer Res Clin Oncol. 2011;137(1):131-7.

42. Zhang J, Chang DY, Mercado-Uribe I, Liu J. Sex-determining region Y-box 2 expression predicts poor prognosis in human ovarian carcinoma. Hum Pathol. 2012;43(9):1405-12

43. Bareiss PM, Paczulla A, Wang H, Schairer R, Wiehr S, Kohlhofer U, Rothfuss OC, Fischer A, Perner S, Staebler A, Wallwiener D, Fend F, Fehm T, Pichler B, Kanz L, Quintanilla-Martinez L, Schulze-Osthoff K, Essmann F, Lengerke C. SOX2 expression associates with stem cell state in human ovarian carcinoma. Cancer Res. 2013:73(17):5544-55.

44. Rybak AP, Tang D. SOX2 plays a critical role in EGFR-mediated self-renewal of human prostate cancer stem-like cells. Cell Signal. 2013;25(12):2734-42.

45. Santini R. Pietrobono, S., Pandolfi, S., Montagnani, V., D'Amico, M., Penachioni, J. Y.. Vinci, M. C., Borgognoni, L., Stecca, B. SOX2 regulates selfrenewal and tumorigenicity of human melanoma-initiating cells. Oncogene. 2014;33(38):4697-708.

46. Weina K, Utikal J. SOX2 and cancer: current research and its implications in the clinic. Clin Transl Med. 2014;3:19.

47. Vazquez-Martin A. Cufi, S., Lopez-Bonet, E., Corominas-Faja, B., Cuyas, E., Vellon, L., Iglesias, J. M., leis, O., Martin, A. G., Menendez, J. a. reprogramming of nongenomic estrogen signaling by the stemness factor SOX2 enhances the tumor-initiating capacity of breast cancer cells. Cell Cycle. 2013;12(22):3471-7.

48. Fields AP, Justilien V, Murray NR. The chromosome 3926 OncCassette: a multigenic driver of human cancer. Adv Biol Regul. 2016;60:47-63.

49. Wang J. Qian, J., Hoeksema, M. D., Zou, Y., Espinosa, A. V., Rahman, S. M. Zhang, B., Massion, P. P. integrative genomics analysis identifies candidate drivers at 3q26-29 amplicon in squamous cell carcinoma of the lung. Clin Cancer Res. 2013;19(20):5580-90.

50. Davidson MA, Shanks EJ. 3q26-29 amplification in head and neck squamous cell carcinoma: a review of established and prospective oncogenes. FEBS J. 2017;284(17):2705-31.

51. Chaluvally-Raghavan P, Zhang F, Pradeep S, Hamilton MP, Zhao X, Rupaimoole R, Moss T, Lu Y, Yu S, Pecot CV, Aure MR, Peuget S, RodriguezAguayo C, Han HD, Zhang D, Venkatanarayan A, Krohn M, Kristensen VN, Gagea M, Ram P, Liu W, Lopez-Berestein G, Lorenzi PL, Borresen-Dale AL, Chin K, Gray J, Dusetti NJ, McGuire SE, Flores ER, Sood AK, Mills GB. Copy number gain of hsa-miR-569 at 3q26.2 leads to loss of TP53INP1 and aggressiveness of epithelial cancers. Cancer Cell. 2014;26(6):863-79.

52. Cerami E. Gao, J., Dogrusoz, U., gross, B. E., Sumer, S. O., Aksoy, B. a., Jacobsen, a., Byrne, C. J., Heuer, M. L., Larsson, E., Antipin, Y., Reva, B., Goldberg, A. P., Sander, C., Schultz, N. the cBio cancer genomics portal: an open platform for exploring multidimensional cancer genomics data. Cancer Discov. 2012;2(5):401-4.

53. Gao J, Aksoy BA, Dogrusoz U, Dresdner G, Gross B, Sumer SO, Sun Y, Jacobsen A, Sinha R, Larsson E, Cerami E, Sander C, Schultz N. Integrative 
analysis of complex cancer genomics and clinical profiles using the cBioPortal. Sci Signal. 2013;6(269):pl1.

54. Tainsky MA. Yim, S. O., Krizman, D. B., Kannan, P., Chiao, P. J., Mukhopadhyay, T., Buettner, R. modulation of differentiation in PA-1 human teratocarcinoma cells after N-ras oncogene-induced tumorigenicity. Oncogene. 1991;6(9): 1575-82.

55. Shaw TJ, Senterman MK, Dawson K, Crane CA, Vanderhyden BC. Characterization of intraperitoneal, orthotopic, and metastatic xenograft models of human ovarian cancer. Mol Ther. 2004;10(6):1032-42.

56. Beaufort CM, Helmijr JC, Piskorz AM, Hoogstraat M, Ruigrok-Ritstier K, Besselink N, Murtaza M, van IJWF, Heine AA, Smid M, Koudijs MJ, Brenton JD, Berns EM, Helleman J. Ovarian cancer cell line panel (OCCP): clinical importance of in vitro morphological subtypes. PloS one. 2014;9(9):e103988.

57. Domcke S, Sinha R, Levine DA, Sander C, Schultz N. Evaluating cell lines as tumour models by comparison of genomic profiles. Nat Commun. 2013;4:2126.

58. Tripathi SC, Fahrmann JF, Celiktas M, Aguilar M, Marini KD, Jolly MK, Katayama $\mathrm{H}$, Wang $\mathrm{H}$, Murage EN, Dennison JB, Watkins DN, Levine $\mathrm{H}$, Ostrin EJ, Taguchi A, Hanash SM. MCAM Mediates Chemoresistance in small-cell lung Cancer via the PI3K/AKT/SOX2 signaling pathway. Cancer Res. 2017;77(16):4414-25.

59. Wen Y, Hou Y, Huang Z, Cai J, Wang Z. SOX2 is required to maintain cancer stem cells in ovarian cancer. Cancer Sci. 2017;108(4):719-31.

60. Zhang S, Cui W. Sox2, a key factor in the regulation of pluripotency and neural differentiation. World J Stem Cells. 2014;6(3):305-11.

61. Avilion AA, Nicolis SK, Pevny LH, Perez L, Vivian N, Lovell-Badge R. Multipotent cell lineages in early mouse development depend on SOX2 function. Genes Dev. 2003;17(1):126-40.

62. Zhou C, Yang X, Sun Y, Yu H, Zhang Y, Jin Y. Comprehensive profiling reveals mechanisms of SOX2-mediated cell fate specification in human ESCS and NPCs. Cell Res. 2016;26(2):171-89.

63. Tsankov AM, Gu H, Akopian V, Ziller MJ, Donaghey J, Amit I, Gnirke A, Meissner A. Transcription factor binding dynamics during human ES cell differentiation. Nature. 2015;518(7539):344-9.

64. Watanabe H, Ma Q, Peng S, Adelmant G, Swain D, Song W, Fox C, Francis JM, Pedamallu CS, DeLuca DS, Brooks AN, Wang S, Que J, Rustgi AK, Wong KK, Ligon KL, Liu XS, Marto JA, Meyerson M, Bass AJ. SOX2 and p63 colocalize at genetic loci in squamous cell carcinomas. J Clin Invest. 2014; 124(4):1636-45.

65. Yevshin I, Sharipov R, Kolmykov S, Kondrakhin Y, Kolpakov F. GTRD: a database on gene transcription regulation-2019 update. Nucleic Acids Res. 2019;47(D1):D100-D5.

66. Lodato MA, Ng CW, Wamstad JA, Cheng AW, Thai KK, Fraenkel E, Jaenisch R, Boyer LA. SOX2 co-occupies distal enhancer elements with distinct POU factors in ESCs and NPCs to specify cell state. PLoS Genet. 2013;9(2): e1003288.

67. Zhang Y. Wong, C. H., Birnbaum, R. Y., Li, G., Favaro, R., Ngan, C. Y., Lim, J., tai, E., Poh, H. M., Wong, E., Mulawadi, F. H., sung, W. K., Nicolis, S., Ahituv, N., Ruan, Y., Wei, C. L. chromatin connectivity maps reveal dynamic promoterenhancer long-range associations. Nature. 2013;504(7479):306-10.

68. Wei CL, Nicolis SK, Zhu Y, Pagin M. Sox2-dependent 3D chromatin Interactomes in transcription, neural stem cell proliferation and neurodevelopmental diseases. J Exp Neurosci. 2019;13:1-6.

69. Maucksch C, Jones KS, Connor B. Concise review: the involvement of SOX2 in direct reprogramming of induced neural stem/precursor cells. Stem Cell Transl Med. 2013;2(8):579-83.

70. Wuebben EL, Rizzino A. The dark side of SOX2: cancer - a comprehensive overview. Oncotarget. 2017:8(27):44917-43.

71. Pevny LH, Nicolis SK. Sox2 roles in neural stem cells. Int J Biochem Cell Biol. 2010;42(3):421-4

72. Goolam M, Scialdone A, Graham SJL, Macaulay IC, Jedrusik A, Hupalowska A, Voet T, Marioni JC, Zernicka-Goetz M. Heterogeneity in Oct4 and Sox2 targets biases cell fate in 4-cell mouse embryos. Cell. 2016;165(1):61-74.

73. Liu K, Lin B, Zhao M, Yang X, Chen M, Gao A, Liu F, Que J, Lan X. The multiple roles for Sox2 in stem cell maintenance and tumorigenesis. Cell Signal. 2013;25(5):1264-71.

74. Lou X, Han X, Jin C, Tian W, Yu W, Ding D, Cheng L, Huang B, Jiang H, Lin B. SOX2 targets fibronectin 1 to promote cell migration and invasion in ovarian cancer: new molecular leads for therapeutic intervention. OMICS. 2013;17(10):510-8.

75. Qian J, Massion PP. Role of chromosome $3 q$ amplification in lung cancer. Thorac Oncol. 2008;3(3):212-5.
76. Ballabio S, Craparotta I, Paracchini L, Mannarino L, Corso S, Pezzotta MG, Vescio M, Fruscio R, Romualdi C, Dainese E, Ceppi L, Calura E, Pileggi S, Siravegna G, Pattini L, Martini P, Delle Marchette M, Mangioni C, Ardizzoia A, Pellegrino A, Landoni F, D'Incalci M, Beltrame L, Marchini S. Multisite analysis of high-grade serous epithelial ovarian cancers identifies genomic regions of focal and recurrent copy number alteration in 3q26.2 and 8q24.3. Int J Cancer. 2019;145(10):2670-81.

77. Sonoda G, Palazzo J, du Manoir S, Godwin AK, Feder M, Yakushiji M, et al. Comparative genomic hybridization detects frequent overrepresentation of chromosomal material from 3q26, 8q24, and 20q13 in human ovarian carcinomas. Genes Chromosomes Cancer. 1997:20(4):320-8.

78. Gen Y, Yasui K, Zen Y, Zen K, Dohi O, Endo M, Tsuji K, Wakabayashi N, Itoh Y, Naito Y, Taniwaki M, Nakanuma Y, Okanoue T, Yoshikawa T. SOX2 identified as a target gene for the amplification at $3 q 26$ that is frequently detected in esophageal squamous cell carcinoma. Cancer Genet Cytogenet. 2010;202(2):82-93.

79. Wilting SM, de Wilde J, Meijer CJ, Berkhof J, Yi Y, van Wieringen WN, Braakhuis BJ, Meijer GA, Ylstra B, Snijders PJ, Steenbergen RD. Integrated genomic and transcriptional profiling identifies chromosomal loci with altered gene expression in cervical cancer. Genes Chromosomes Cancer. 2008;47(10):890-905

80. Guan X-Y, Sham JS, Tang TC, Fang Y, Huo K-K, Yang J-M. Isolation of a novel candidate oncogene within a frequently amplified region at $3 q 26$ in ovarian cancer. Cancer Res. 2001;61(9):3806-9.

81. Ma L, Lai D, Liu T, Cheng W, Guo L. Cancer stem-like cells can be isolated with drug selection in human ovarian cancer cell line SKOV3. Acta Biochim Biophys Sin Shanghai. 2010;42(9):593-602.

82. Ohnuki M, Tanabe K, Sutou K, Teramoto I, Sawamura Y, Narita M, Nakamura M, Tokunaga Y, Nakamura M, Watanabe A, Yamanaka S, Takahashi K. Dynamic regulation of human endogenous retroviruses mediates factorinduced reprogramming and differentiation potential. Proc Natl Acad Sci U S A. 2014;111(34):12426-31.

83. Lister R, Pelizzola M, Dowen RH, Hawkins RD, Hon G, Tonti-Filippini J, Nery JR, Lee L, Ye Z, Ngo QM, Edsall L, Antosiewicz-Bourget J, Stewart R, Ruotti V, Millar AH, Thomson JA, Ren B, Ecker JR. Human DNA methylomes at base resolution show widespread epigenomic differences. Nature. 2009; 462(7271):315-22

84. Gifford CA, Ziller MJ, Gu H, Trapnell C, Donaghey J, Tsankov A, Shalek AK, Kelley DR, Shishkin AA, Issner R, Zhang X, Coyne M, Fostel JL, Holmes L, Meldrim J, Guttman M, Epstein C, Park H, Kohlbacher O, Rinn J, Gnirke A, Lander ES, Bernstein BE, Meissner A. Transcriptional and epigenetic dynamics during specification of human embryonic stem cells. Cell. 2013; 153(5):1149-63.

85. Le Marer N, Laudet V, Svensson EC, Cazlaris H, Van Hille B, Lagrou C, Stehelin D, Montreuil J, Verbert A, Delannoy P. The C-Ha-ras oncogene induces increased expression of beta-galactoside alpha-2, 6-sialyltransferase in rat fibroblast (FR3T3) cells. Glycobiology. 1992;2(1):49-56.

86. Seales EC, Jurado GA, Singhal A, Bellis SL. Ras oncogene directs expression of a differentially sialylated, functionally altered beta1 integrin. Oncogene. 2003:22(46):7137-45.

87. Johansson P, Pavey S, Hayward N. Confirmation of a BRAF mutationassociated gene expression signature in melanoma. Pigment Cell Res. 2007; 20(3):216-21.

88. Lu J, Isaji T, Im S, Fukuda T, Hashii N, Takakura D, Kawasaki N, Gu J. betaGalactoside alpha2,6-sialyltranferase 1 promotes transforming growth factorbeta-mediated epithelial-mesenchymal transition. J Biol Chem. 2014;289(50): 34627-41.

89. Dalziel M, Lemaire S, Ewing J, Kobayashi L, Lau JT. Hepatic acute phase induction of murine beta-galactoside alpha 2,6 sialyltransferase (ST6Gal I) is IL-6 dependent and mediated by elevation of exon $\mathrm{H}$-containing class of transcripts. Glycobiology. 1999:9(10):1003-8.

90. Hanasaki K, Varki A, Stamenkovic I, Bevilacqua MP. Cytokine-induced betagalactoside alpha-2,6-sialyltransferase in human endothelial cells mediates alpha 2,6-sialylation of adhesion molecules and CD22 ligands. J Biol Chem 1994;269(14):10637-43.

\section{Publisher's Note}

Springer Nature remains neutral with regard to jurisdictional claims in published maps and institutional affiliations. 